Cadernos de Semiótica Aplicada

Vol. 4.n.2, dezembro de 2006

\title{
Os jogos eletrônicos como plataforma para o ciberativismo: \\ Estudo de caso do McDonald's Videogame
}

\section{Computer games as an interface for ciberactivism:}

A study of case for Mcdonald's Videogame

Camila Wenzel e Dimas Tadeu de Lorena Filho

UFJF - Universidade Federal de Juiz de Fora

Resumo: Este trabalho apresenta a hipótese das plataformas dos jogos eletrônicos serem utilizadas no ativismo global via hipermídia, através do estudo do McDonald's Videogame. Procuramos estudar a proliferação de signos na hipermídia, os jogos online e o atual ativismo global para descobrir se usuários da hipermídia e/ou jogos eletrônicos conseguem visualizar o caráter ativista do jogo.

Palavras-chave: jogos eletrônicos; hipermídia; ciberativismo; semiótica

\begin{abstract}
This paper presents the hypothesis of the interface of computer games being used to global activism. Studying McDonald's Videogame as an example, we research the spreading of signs through hypermedia, the online games and nowadays global activism to find out if the users of hypermedia, as well as game players, can realize the political characteristics of the game.
\end{abstract}

Key-words: eletronic games; hypermedia; ciberactivism; semiotics 


\section{A hipermídia como complexo sígnico}

Mais do que uma rede de informação, a hipermídia ${ }^{1}$ aparece atualmente como um complexo de signos. Usando um só "suporte" ou linguagem (o sistema binário de zeros e uns), é possível veicular qualquer tipo de mensagem: texto, vídeos, figuras, sons. Essa nova possibilidade criou uma semiosfera mais complexa do que qualquer outra vista anteriormente. Semiosfera seria a "esfera" ou ambiente no qual estão "diluídos" os signos, bem como é onde ocorre a semiosis, isto é, o processo de interpretação sígnica. Debray (1995) tratou, por exemplo, da logosfera (semiosfera da fala), da grafosfera (semiosfera da escrita) e da videosfera (a do vídeo). A hipermídia seria, então, uma nova semiosfera, que dos tempos contemporâneos.

Os signos híbridos da hipermídia aparecem como um bombardeio de informação, que sujeita o internauta a freqüentes processos de semiose, que poderemos chamar de "leitura". Santaella (2004) categoriza três tipos de leitores: o contemplativo, o movente e o imersivo.

O primeiro tipo de leitor é aquele da era do livro. Ele lê, medita, "tem diante de si objetos e signos duráveis, imóveis, localizáveis, manuseáveis."( SANTAELLA, 2004, p. 24). Tem ligação com a cultura letrada e a terceiridade. O leitor movente é aquele da era moderna. Ele está em contato com signos e objetos que se movem, mensagens publicitárias, televisores, automóveis, o que existe em torno dele. É o homem fragmentado, mergulhado na semiosfera urbana, algo que lembra o flâneur de Baudelaire. Está ligado à existência, à simultaneidade e à secundidade.

Finalmente, o leitor imersivo é esse que desponta com a hipermídia. Mais do que se concentrar numa mensagem, ou se mover entre várias, o leitor virtual navega num mundo onde sua subjetividade se fragmenta ao extremo. Ele está em contato com signos concomitantes, mensagens sobrepostas e, portanto, tem inúmeros "sujeitos" convergidos em si. Como o internauta que, ao criar um "avatar", se vê num novo mundo, o leitor imersivo, como o nome sugere, imerge no mar de signos fornecidos pela hipermídia. Algo que faz lembrar, na esfera do ativismo político lúdico, identidades coletivas como Luther Blissett, na década de 90 do século XX. É portanto ligado à indeterminação, à primeiridade. Nas palavras de Santaella (2004, p.33):

Trata-se, na verdade, de um leitor implodido cuja subjetividade se mescla na hipersubjetividade de infinitos textos num grande caleidoscópio tridimensional onde cada novo nó e nexo pode conter uma outra grande rede numa outra dimensão. Enfim, o que se tem aí é um universo novo.

É a hipermídia, portanto, uma nova forma de representação e a crescente tecnologia, suporte dessa semiosfera, só tende a aumentar a hibridização e a variedade de signos por ela veiculados. É neste contexto que se encontram, entre outros meios, os jogos eletrônicos, plataforma hipermidiática aqui escolhida para estudo.

\footnotetext{
${ }^{1} \mathrm{O}$ termo hipermídia designa um tipo de escritura complexa, na qual diferentes blocos de informação estão interconectados. Devido a características do meio digital, é possível realizar trabalhos com uma quantidade enorme de informações vinculadas, criando uma rede multidimensional de dados. Essa rede, que constitui o sistema hipermidiático propriamente dito, possibilita ao leitor diferentes percursos de leitura (LEÃO, 1999, p. 9)
} 


\section{Jogos eletrônicos e ciberativismo}

Games ou jogos eletrônicos para computador baseiam-se na tecnologia mais avançada de computação gráfica, design de interface, dispositivos de informação e entrada de dados, inteligência artificial e arte. Suas principais características acabam nos mostrando porque os jogos exercem fascinação e têm se tornado cada vez mais objeto de pesquisa: imersão, agenciamento, design de interface, interação, presença e múltiplas identidades.

Hoje, os jogos eletrônicos evoluem cada vez mais rápido, criando um verdadeiro mundo paralelo:

Um mundo virtual paralelo à realidade concreta. Os fenômenos físicos e de luminosidade e textura, gravidade e som, sendo simulados com tanta perfeição, a ponto de tornarem-se capazes de iludir todos os sentidos humanos. O simulacro ou a ciberrealidade. Um universo de átomos e moléculas criado por sinais elétricos numa interface digital (VILLAS BÔAS, 2005, p. 17)

Em outro artigo defendemos que a plataforma dos jogos eletrônicos online poderia ser utilizada para um ativismo via hipermídia, visto que as principais características dos games online podem ser aproximadas com o atual ativismo global. (WENZEL, 2005).

$\mathrm{O}$ atual ativismo global caracteriza-se por manifestações que acontecem nas ruas de países que sediam encontros de organizações e símbolos do capitalismo, como OMC, FMI, Banco Mundial e McDonald's, entre outros. Nesses dias, a rua é tomada por uma mistura de festa, sabotagem urbana, rave, performance artísticas, com o bloqueio de ruas e praças. A rua, que ao longo dos anos foi sendo privatizada pelo capitalismo, novamente é resgatada pelo povo. Este que foi recolocado em shoppings e outros pontos de vendas deixa de caminhar nas calçadas, quebra a ordem que reina nos grandes centros e se reapropria do ambiente.

$\mathrm{O}$ ativismo global vem utilizando politicamente a Internet, que é também um grande instrumento da globalização. Através dela, podem-se espalhar idéias e estabelecer contatos com outros países a custo baixo, permitindo que pequenos grupos em diversos lugares do mundo divulguem suas mensagens, troquem informações e articulem ações conjuntas ou simultâneas.

Analisando, porém, alguns sites ativistas como o Centro de Mídia Independente, o Indymedia, que nasceram com o atual movimento ativista a partir da necessidade de gerar informações alternativas sobre os acontecimentos e considerando-se que a grande mídia tenta encobrir objetivos e propostas distorcendo as manifestações, podemos perceber que as ferramentas hipermidiáticas não são exploradas de maneira a recriar o ambiente lúdico e festivo presente nas manifestações de rua. Os protestos atuais que são uma mistura de festa e sabotagem urbana, com fantasias, música, performance artística e até escola de samba são substituídos virtualmente por sites que se apóiam predominantemente no verbal, com layout tradicional, fontes pequenas, cores neutras, poucas fotos e sem animações. Em vez de se recriar um ambiente não oficial e libertário, como as festas e os jogos, presentes nas manifestações, há uma afirmação das estruturas organizacionais do mundo extra Internet.

Experimentos como o site Euromayday que, em 2004, construindo avatares digitais a serem escolhidos pelos manifestantes que participavam de uma passeata online; apropriações criativas por parte de usuários de games que criam possibilidades muitas das vezes não pensadas pelos programadores como concursos de beleza e festas dentro dos jogos em rede; sabotagem de hackers que mudam procedimentos dos jogos, onde um tiro em um game torna-se um envio de e-mail contra a guerra para o presidente dos Estados Unidos. Com base em alguns desses exemplos, visualizamos que as plataformas dos jogos 
eletrônicos, uma plataforma de fácil utilização, ambientes criativos e envolventes é uma possibilidade de ciberativismo que já vem sendo usada, mas deve ser mais desenvolvida numa tentativa de trazer para a rede mundos tão próximos como os jogos e o ativismo.

Dessa forma buscamos perceber, por meio da análise do jogo "McDonald's Videogame", se a construção de jogos com caráter ativista pode ser eficaz, na medida em que os usuários da hipermídia são capazes de analisar e interpretar determinados signos do jogo.

\section{Análise semiótica do McDonald's Videogame}

Escolheu-se para a análise o jogo online McDonald's Videogame. Veiculado pelo site ativista italiano Molle Industria, - http://www.molleindustria.org - responsável pelo desenvolvimento de jogos com caráter político e pela realização da passeata online Euromayday, o game coloca o jogador na posição de dono da cadeia McDonald's. A atividade de administração vai desde o cultivo de soja e criação de gado para abate, passando pelo matadouro, pelas lanchonetes e chegando até o setor financeiro, de marketing e relações públicas. O principal objetivo do game é aferir lucro - independentemente de como. Para manter o saldo positivo, o jogador precisará infringir a lei através de subornos, desmatamentos, invasão de reservas indígenas, deixando assim explícitas as políticas do McDonald's - condenadas pelos ativistas.

Os jogos eletrônicos trazem uma farta dose de signos, ou, como já foi dito outrora, são "cada vez mais um complexo emaranhado de linguagens, narrativas e (...) ideologias".(LORENA, 2005) Desde o cenário do jogo e os personagens, até a narrativa do jogo em si, tudo é signo. No caso de McDonald's Videogame, eles assumem uma importância ainda maior, já que o caráter irônico do jogo é definido justamente por signos - símbolos em sua maioria. Para Santaella:

O símbolo é um signo cuja virtude está na generalidade da lei, regra, hábito ou convenção de que ele é portador e a função como signo dependerá precisamente dessa lei ou regra que determinará seu interpretante. (SANTAELLA, 2000, p. 132).

No caso do McDonald's Videogame, o caráter simbólico predomina, pois, para se chegar ao interpretante de que tudo é uma ironia, é preciso ter conhecimento de conceitos culturalmente assimilados, como o de que o McDonald's seria uma companhia de políticas corruptas e inescrupulosas ou de que subornar autoridades pode repercutir em favor de uma empresa - se não descoberto, claro. É essa capacidade de inferir do jogo seu caráter maior que procuramos medir por meio de nossa pesquisa.

Analisemos primeiramente os signos do jogo por si mesmos. Tudo é muito colorido. Os gráficos são bonitos, as formas são chapadas e sem contornos. Há uma predominância de formas arredondadas e arestas suavizadas, além de uma espécie de quebra de linhas retas através de linhas "rugosas".

Mas é na análise do signo em relação ao seu objeto que repousa a verdadeira ironia do jogo, bem como seus detalhes mais interessantes. Chama atenção, logo na tela de início do game, o uso da logomarca do McDonald's. O símbolo por excelência da rede de lanchonetes (e, para alguns, do imperialismo capitalista) vem com o slogan trocado. De "I'm loving $i t^{2}$ ",

\footnotetext{
2 "Eu estou amando isso", ou, na versão brasileira, "Amo muito tudo isso".
} 


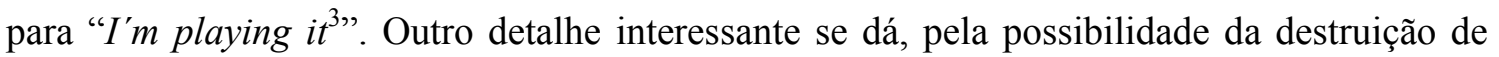
florestas e reservas indígenas para a plantação de soja ou criação de gado. Esta devastação aparece como símbolo (irônico) das políticas da companhia, refletidas em todo o jogo. Seja na revolta dos funcionários da lanchonete (que, se insatisfeitos, cospem no lanche, e nesse caso, o jogador pode escolher demiti-los ou repreendê-los), seja pela possibilidade de subornar autoridades para que a empresa não sofra - ou sofra menos - prejuízos, as práticas politicamente incorretas aparecem no jogo o tempo todo. Escamoteadas, porém, pelo visual agradável e pelo lúdico da própria atividade de jogar, elas aparecem como normais, ou pelo menos aceitáveis, para quem o joga.

Neste sentido, um aspecto bastante interessante, principalmente devido ao seu caráter político, se dá pela esporádica aparição de ativistas ao longo do jogo. Quando se destrói uma área de proteção ambiental para fazer pastagens, por exemplo, é comum que o jogador se depare com uma tela em que ambientalistas protestam furiosamente. Outra situação comum acontece quando pessoas obesas protestam contra a comida servida nas lanchonetes, muito calórica e nociva à saúde. Para contornar estes problemas o jogador precisa lançar mão de recursos como o suborno de políticos, médicos, ambientalistas e outras autoridades, além de pagar por campanhas de marketing, como "McDonald's no terceiro mundo". Se apenas aí a ironia do jogo não salta aos olhos, ela pode fazê-lo quando se observa a imagem associada (como símbolo) à referida campanha: uma caricatura do mascote da rede McDonald's (O palhaço Ronald McDonald) oferece um sanduíche a uma criança africana.

Mergulhado na atmosfera do game, o jogador se encontra, portanto na posição de administrador da rede de lanchonetes, e conseqüentemente, pode vir a incorporar também a ganância por lucro, não se importando, por exemplo, em derrubar áreas de reserva ambiental.

Ainda sobre os signos, é interessante notar como o som é ambientado de forma caricata. Há música animada (quase adolescente) na lanchonete, conversas de pessoas nos escritórios, passarinhos no campo e até tambores na aldeia indígena. Tudo parece ser organizado em torno de estereótipos ${ }^{4}$. Num outro momento, (quando se perde o jogo) uma imagem de Ronald McDonald, juntamente com os acionistas, todos de expressão aborrecida, aparece informando que a companhia faliu.

Há também relações icônicas com outros meios. A forma como o game é desenhado, por exemplo, lembra muito uma história em quadrinhos em movimento, ou mesmo as personagens de South Park (desenho animado americano de crítica social irônica). Outra relação que pode ser estabelecida é entre as personagens do game e o tradicional brinquedo "Playmobil". Essa semelhança também reforçaria o caráter irônico do game na medida em que transforma todos os funcionários da rede em joguetes (literalmente) de reações previsíveis e submetidos aos comandos do jogador (o que efetivamente acontece).

\section{O experimento}

Buscando perceber se os signos do McDonald's Videogame eram interpretados pelos jogadores como signos de ironia - identificando assim o game com a causa ativista -

\footnotetext{
3 "Estou jogando isso"

${ }^{4}$ Como se pode perceber quando aparece o Ronald McDonald entregando um sanduíche a uma criança negra africana, desnutrida e em trajes pequenos e velhos, durante uma campanha publicitária da empresa em países do terceiro mundo.
} 
desenvolvemos um experimento aplicado numa LAN house do bairro São Mateus, em Juiz de Fora-MG, no dia 20 de maio de 2006. A metodologia consistiu em apresentar o jogo aos participantes e em seguida deixá-los jogar até que o jogo acabasse. Em seguida, os participantes eram submetidos a um questionário de identificação e uma entrevista sobre o jogo, que buscava elucidar as principais impressões do jogador, esta última com registro sonoro. O questionário de identificação continha os seguintes dados:

- Nome

- Idade

- Grau de Escolaridade

- Freqüência de uso da Internet

- Os jogos prediletos

- A freqüência com que se joga

A entrevista sobre o jogo era composta pelas seguintes questões:

1) O que você achou do jogo?

2) Você teve alguma dúvida em relação ao jogo?

3) Você acha que o jogo se parece com a realidade? (Você acha que o dono do Mcdonald's realmente age dessa forma?) Por quê?

4) O que você mais gostou no jogo?

Foram selecionados dez participantes para o experimento, na faixa etária entre 8 e 34 anos $^{5}$. Todos os participantes foram escolhidos aleatoriamente na própria $L A N$ house, pois se buscava o perfil médio do usuário da hipermídia e/ou dos jogos eletrônicos. O número de participantes (10), foi suficiente para chegar a uma conclusão, já que as constatações foram as mesmas em todos os casos.

Quando da apresentação do jogo, não se explicava sua origem, isto é, sua natureza ativista, porém explicitava-se que o jogo não tratava de algo feito pela rede McDonald's. Neste momento, as regras eram apresentadas por meio do próprio jogo e alguns textos eram traduzidos, uma vez que o jogo é em inglês. A partir daí, o participante podia jogar livremente, tendo seu tempo cronometrado e seu desempenho observado e registrado.

O principal fato constatado é que todos os participantes interpretaram o jogo como sendo um game de simulação, cuja intenção principal seria administrar a rede McDonald's. Em nenhum momento houve referência ao ativismo ou à ironia do jogo. Em reposta à pergunta 1, por exemplo, Bruno José de Santana, 13 anos, disse: "Achei legal, porque a gente aprende a administrar uma firma". Opinião idêntica à do graduando em Filosofia, Sandro Santiago, 34 anos: "Acho que o jogo é mais para quem faz administração, pra quem é da área da economia". Nesse sentido, também foi interessante observar que não houve nenhuma dúvida sobre os reais objetivos do jogo. As únicas dúvidas constatadas diziam respeito à jogabilidade em si: "Sim, como dar comida às vacas", respondeu Gabriel da Cunha, 13 anos, à pergunta número 2 .

A presença dos ativistas no jogo também deu margem a observações importantes. Enquanto alguns simplesmente ignoravam sua aparição, fechando a janela, outros iam direto ao setor de relações públicas, ativando a opção de suborno às autoridades. Foi o ocorrido, por exemplo, com Gabriel Botte de Paula, 8 anos: "É só pagar as pessoas que os moços de cara feia vão embora". No entanto, mesmo nesse caso, fica claro que não havia uma real consciência do porquê da presença dos ativistas ou implicações de um suborno, ali usado como um simples eliminador de obstáculos no game.

\footnotetext{
${ }^{5}$ Aos menores foi solicitada autorização dos responsáveis legais para publicação dos nomes e depoimentos em registro sonoro.
} 
A ética presente nas ações dos participantes foi, aliás, bastante curiosa. Embora o ambiente do jogo permitisse uma transgressão da ética sem que houvesse uma punição fora do game, nem sempre se agia da forma "errada", ainda que fosse a mais adequada para se lucrar. Um exemplo interessante foi o de Yasmim Figueredo Barbosa, 15 anos, que, mesmo tendo esgotadas as terras cultiváveis, se recusou a desmatar ou invadir a reserva indígena. "(...) achei muito interessante o negócio dos ambientalistas, de a gente não poder fazer tudo sem que eles reclamassem", disse Yasmim em resposta à pergunta 3. Cabe aqui outra observação a respeito da ética dentro do jogo. De acordo com o comportamento dos participantes, pareceu ser muito mais grave desmatar e invadir reservas indígenas do que o suborno de autoridades. Embora nem todos os jogadores tenham desmatado - apesar de saber que podiam fazê-lo todos eles lançaram mão do suborno, sempre como algo óbvio ou aceitável.

Os caráteres imersivo e lúdico do jogo foram comprovados pelo experimento. Imersivo porque o jogo ofereceu aos jogadores submetidos à experiência a possibilidade de assumir a identidade do administrador da cadeia McDonald's. A subjetividade do jogador é, aliás, implodida em favor daquelas propostas pelo hiper espaço do jogo, tornado-o não apenas o diretor da empresa como também, por ventura, fazendo-o pensar como agricultor, funcionário de lanchonete ou profissional de marketing. Lúdico porque o jogo pareceu agradável e atrativo aos jogadores. Em resposta à pergunta 1, por exemplo, Bruno César Campos, 18 anos, disse: "Acho que o jogo foi bem elaborado. Gostei da interatividade, da capacidade de você se sentir um administrador do McDonald's. Gostei do gráfico.”. Opinião parecida com a de Yasmim: "Achei bonitinho, interessante". Observando os participantes enquanto jogavam, a interatividade ficava mais clara. Bruno José, quando viu um dos funcionários da lanchonete cuspindo no lanche, gritou irritado: "Manda ele embora!".

\section{Considerações finais}

Observamos por meio deste experimento que o McDonald's Videogame se mostrou ineficaz em seu real objetivo: o de ser um jogo ativista, que funcionasse como uma crítica às políticas neoliberais adotadas por uma grande empresa capitalista como o McDonald's. Desde uma criança de 8 anos até um graduando em Filosofia, de 34 anos - que depois da entrevista se disse contra o McDonald's e o imperialismo americano - nenhum participante foi capaz de identificar os signos do jogo como uma ironia ou crítica. As possíveis razões para esse fato seriam:

1) A própria natureza imersiva do McDonald's Videogame. Dentre os três tipos de leitores identificados por Santaella, o jogador deste game se enquadra no terceiro tipo, o imersivo. Exatamente porque este tipo de leitor encara os signos que lhe são apresentados como uma realidade, não há reflexão sobre eles. O jogador participa do signo, existe dentro dele no ato do jogo. Numa possível comparação pode-se citar o ato de andar. Para quem anda, o "andar" dificilmente será objeto de reflexão, um processo de significação. Entretanto, para um deficiente físico, ou para um médico, por exemplo, (leitores contemplativos com relação ao "andar") o "andar" pode ser um signo, desencadear uma semiose. No momento em que se joga o McDonald's Videogame, antes que se possa refletir sobre as implicações que existem no fato de alguém ser o dono da cadeia de lanchonetes, sabe-se que se se é o dono, é preciso ganhar dinheiro e fazer a companhia prosperar. Esse parece ser, portanto, o principal objetivo do jogo, que acaba mascarando sua natureza ativista e mesmo revertendo-a, o que resulta numa transformação do game em propaganda de uma idéia oposta àquela a partir da qual o jogo havia sido criado. Entre os entrevistados, a maioria dos jogadores gostou de ser o dono 
do McDonald's. Para o efeito desejado, o ideal seria que o game fosse apresentado sob a ótica do ativista e não sob a do administrador da cadeia de lanchonetes.

2) Os signos que remetem ao ativismo não são suficientemente claros. Seja pela própria estética agradável do jogo - que escamoteia seu caráter "sério" - seja pela falta de experiência colateral dos jogadores em relação à natureza ativista do game, em nenhum momento os signos foram suficientes para deixar clara a proposta do game. Agir de forma ilícita (subornar e desmatar) ou duvidosa (usar hormônio na comida das vacas), fazer campanhas de marketing no terceiro mundo, plantar soja transgênica, despedir e contratar funcionários displicentemente pareceu, na maioria das vezes, admissível e natural, uma vez que nenhum jogador conseguiu chegar ao sentido que, dizia-se, o jogo pretendia defender. $\mathrm{O}$ que se pôde observar ao analisar as respostas dos jogadores que usaram o game foi que havia acontecido exatamente o oposto do que se desejou transmitir, isto é, uma crítica ou denúncia das políticas do McDonald's. Possivelmente, o uso de signos menos sutis (isto é, mais abrangentes em seu caráter simbólico) tornaria mais clara e eficaz a mensagem transmitida, provavelmente evitando a confusão do jogo com algo favorável ao McDonald's. Em suma, se o objeto do jogo - considerando-o como signo - é o de que o McDonald's adota políticas abusivas e criminosas, este não é, ao menos, o interpretante que corresponde aos participantes do experimento. Possivelmente, isto se dá porque, uma vez que os símbolos não são todos codificados culturalmente da maneira proposta pelo site (isto é, nem todas as pessoas sabem o que é ativismo, ou que o McDonald's adota práticas condenáveis pelos ativistas, ou mesmo que um jogo pode ser usado com fins políticos), eles não são interpretados da maneira adequada.

Concluímos então, tomando por base a análise do McDonald's Videogame e o experimento em questão, que esse jogo não é completamente eficaz como plataforma para o ativismo político. Seja pela idéia - esta sim, codificada fortemente no âmbito cultural - de que um jogo não trata de coisas sérias, seja pela imersão propiciada pelo jogo - que não se conjuga com seu objetivo, neste caso - ou pela inobservância na clareza dos signos, os jogos eletrônicos ainda não atingem a eficácia desejada pelos idealizadores do ciberativismo.

\section{Referências Bibliográficas}

DEBRAY, Régis. Manifestos midiológicos. Petrópolis: Vozes, 1995

LA MOLLEINDUSTRIA. Disponível em http://www.molleindustria.org. Acesso em 20 de maio de 2006

LEÃO, Lucia. O labirinto da hipermídia: Arquitetura e nagevação no ciberspaço. São Paulo: Ilumminuras, 1999.

LORENA, Dimas Tadeu. O jogo como estrutura regulamentar. In Anais do III Encontro Regional de Comunicação, Juiz de Fora: Faculdade de Comunicação da UFJF, 2005.

SANTAELLA, Lucia. A teoria geral dos signos: Como as linguagens significam as coisas. São Paulo: Pioneira, 2000.

Navegar no ciberespaço: O perfil cognitivo do leitor imersivo. São Paulo: Paulus, 2004.

VILLAS BÔAS, Rafael, Mercado de Jogos. In AZEVEDO Eduardo. Desenvolvimento de jogos 3D e aplicações em realidade virtual. São Paulo: Elsevier, 2005. 
CASA, Vol.4, n.2, dezembro de 2006

WENZEL, Camila. Jogos eletrônicos e ativismo global. In Anais do III Encontro Regional de Comunicação, Juiz de Fora: Faculdade de Comunicação da UFJF, 2005. 